\title{
Exposure to cyclooxygenase-2 inhibitors and risk of cancer: nested case-control studies
}

\author{
Y Vinogradova*,', C Coupland' and J Hippisley-Cox' \\ 'Division of Primary Care, 13th Floor, Tower Building, University Park, University of Nottingham, Nottingham, NG7 2RD, UK
}

BACKGROUND: Selective cyclooxygenase-2 (COX2) inhibitors are widely used as analgesics and it is unclear whether its long-term use affects cancer risk.

METHODS: A series of nested case-control studies using the QResearch primary care database. Associations of COX2 inhibitor use with risk of all cancers and 10 common site-specific cancers were estimated using conditional logistic regression adjusted for comorbidities, smoking status, socioeconomic status, and use of non-steroidal anti-inflammatory drugs, aspirin and statins.

RESULTS: A total of 88125 cancers, diagnosed between 1998 and 2008, matched with up to five controls, were analysed. Use of COX2 inhibitors for more than a year was associated with a significantly increased risk of breast cancer (odds ratio (OR) I.24, 95\% confidence interval (Cl) I.08-1.42) and haematological malignancies (OR I.38, 95\% Cl I. I2- I.69) and a decreased risk of colorectal cancer (OR 0.76, 95\% Cl 0.63-0.92). There were no other significant associations.

CONCLUSION: Prolonged use of COX2 inhibitors was associated with an increased risk of breast and haematological cancers and decreased risk of colorectal cancer. These findings need to be confirmed using other data sources.

British Journal of Cancer (201 I) 1 05, 452-459. doi:I0.1038/bjc.20II.252 www.bjcancer.com

Published online 12 July 2011

(C) 201। Cancer Research UK

Keywords: COX2 inhibitors; breast cancer; colorectal cancer; haematological cancers; QResearch

Selective cyclooxygenase-2 (COX2) inhibitors are used for patients intolerant to traditional non-steroidal anti-inflammatory drugs (NSAID), which have gastrointestinal toxic effects (Chan et al, 2010). Being introduced in the United Kingdom in 1985, COX2 inhibitors account for $14 \%$ of all NSAIDs prescriptions (The NHS Information Centre for health and social care, 2008), despite advice from the UK Medicines and Healthcare products Regulatory Agency (MHRA, 2005) about possible cardiovascular adverse effects (Solomon et al, 2005).

Laboratory investigations have suggested mechanisms by which COX2 inhibitors might reduce the risk of cancer (Koki and Masferrer, 2002; Khan and Lee, 2009) for a range of cancers, although animal experiments have not provided consistent support. A recent publication, for example, shows that COX2 inhibitors do not delay or prevent tumour development in breast tissue in a mouse model (Tran-Thanh et al, 2010).

Some observational studies have investigated effects of COX2 inhibitors on cancer risk, but have produced inconsistent results (Arber et al, 2006; Harris et al, 2006, 2007; Hernández-Díaz and García Rodríguez, 2006). For colorectal cancer, a randomised control trial (Arber et al, 2006) showed a 36\% decreased rate of newly detected colorectal adenomas in celecoxib users. Two studies (Harris et al, 2006, 2007) demonstrated risk reductions for breast and lung cancer, but a larger case-control study (Hernández-Díaz and García Rodríguez, 2006) using primary care

*Correspondence: Dr Y Vinogradova;

E-mail: yana.vinogradova@nottingham.ac.uk

Received 10 March 201 I; revised 2 June 201 I; accepted 10 June 20II; published online 12 July 201 I data showed no effect for lung cancer. Effects on other cancers remain unclear.

We designed a series of large-scale nested case-control studies to determine associations between selective COX2 inhibitors and risks of common cancers. We used the QResearch primary care database, which is large, has a representative population and contains data for individual drug exposures and outcomes.

\section{MATERIALS AND METHODS}

\section{Study design, data source and population}

We conducted a series of nested case-control studies using version 20 of the QResearch primary care database (http://www.qresearch.org) containing anonimised clinical records for over 11 million patients registered with 574 UK general practices. The information recorded on the database includes patient demographics (year of birth, sex, sociodemographic data derived from the UK census 2001), characteristics (height, weight, smoking status), clinical diagnoses, symptoms, consultations, referrals, prescribed medications and results of investigations. The database has been validated by comparing birth rates, death rates, consultation rates, prevalence and mortality rates with other data sources, including the General Household Survey and the General Practice Research Database (National Statistics, 2000; Hippisley-Cox et al, 2005).

We initially identified an open cohort of patients registered between 1 Jan 1997 and 1 July 2008 with participating UK general practices. We then selected as cases all those patients in the cohort aged between 30 and 100 years with a first-ever recorded diagnosis of cancer during the study period, identified from diagnostic 
READ codes in patient records (the standard clinical terminology system used in General Practice in the UK (Smith et al, 1995)). Each case was linked to five controls who were alive, had no history of cancer and were registered with the practice at the time of case diagnosis (the index date), matched on age, sex, practice and calendar time using incidence-density sampling.

\section{Exclusions}

Cases with secondary cancers (READ codes: B56, B57, B58) and non-melanoma skin cancer were excluded. For breast cancer, we included only females, and excluded cases and controls with a record of mastectomy or tamoxifen use for more than 12 months before the index date to exclude possible previous diagnoses. We also excluded temporary residents and patients with fewer than 6 years of medical records before the index date to ensure completeness of exposure data.

\section{Primary outcomes}

We analysed cancers overall, and carried out separate analyses for the most common UK cancers (Westlake, 2008): breast (women, B34), prostate (men, B46), lung (B22), colorectal (B13, B14), haematological (B6), bladder (B49), melanoma (B32), gastric (B11), pancreatic (B17) and oesophageal (B10). As haematological malignancies cover a range of diseases, possibly differentially affected by COX2 inhibitors (Nakanishi et al, 2001; Nakamura et al, 2006), we also investigated leukaemia (B63-B6z), lymphoma (B60-B62) and myeloma (B63) separately.

\section{Data}

Records in the year before the index date were ignored to reduce protopathic bias. Prescriptions for cases in this period could relate to early cancer symptoms before the recorded diagnosis. All analyses were, therefore, based only on prescriptions relating to the period between 13 and 72 months before the index date.

We assessed exposure to COX2 inhibitors, including celecoxib, etodolac, etoricoxib, lumiracoxib, rofecoxib, valdecoxib, meloxicam (British Medical Association, Royal Pharmaceutical Society, 2010). We also extracted data on prescriptions for statins, traditional NSAIDs and aspirin because studies have found protective effects of these on various types of cancer (Garcia Rodriguez and Huerto-Alvarez, 2001; Sørensen et al, 2003; Jacobs et al, 2005; Bardia et al, 2007; Gallicchio et al, 2007), in particular, colorectal cancer (Garcia Rodriguez and Huerto-Alvarez, 2001; Sørensen et al, 2003).

We extracted information on age and sex, smoking status (nonsmoker, ex-smoker, current smoker), body mass index (BMI) in $\mathrm{kg} \mathrm{m}^{-2}$, Townsend score (measure of socioeconomic status) and data on comorbidities (cardiovascular disease, hypertension, diabetes, rheumatoid arthritis and osteoarthritis). For breast cancer, we also accounted for previous benign breast disease (fibrocystic disease, intraductal papilloma, fibroadenoma), family history of breast cancer, use of hormone replacement therapy and oral contraceptives. For colorectal cancer, additional comorbidities were ulcerative colitis and Crohn's disease.

We considered patients as COX2 inhibitor users if they had at least one prescription. We estimated cumulative use of COX2 inhibitors by extracting the duration of use for every prescription and, for groups of prescriptions with inter-prescription gaps of less than 60 days; we calculated overall course times from the start of the first prescription to the end of the last prescription. We then calculated cumulative use as the sum of all overall course times and categorised cumulative use for each patient as: no use, less than 90 days, 90 days to 12 months; $13-24$ months; 25-60 months. We also categorised cumulative use as: no use; short-term use (less than 365 days) and long-term use (more than 365 days). A trend test was performed using the actual months of use. We conducted separate analyses for the most common individual COX2 inhibitors - meloxicam, rofecoxib and celecoxib, examining the effect on cancer risk of cumulative use for more than 365 days.

The daily dose of COX2 inhibitors was estimated as the median daily dose of all prescriptions of any COX2 drug recorded. It was categorised by COX2 inhibitor efficacy (Hernández-Díaz and García Rodríguez, 2006) as: high (for celecoxib >200 mg, for meloxicam $>7.5 \mathrm{mg}$, for rofecoxib $>25 \mathrm{mg}$, for etodolac $>400 \mathrm{mg}$, for etoricoxib $>90 \mathrm{mg}$, for valdecoxib $>40 \mathrm{mg}$, for luminoracoxib $>200 \mathrm{mg}$ ); otherwise as low/medium.

The effect on cancer risk of stopping COX2 inhibitors for longterm and short-term users was investigated by determining the last prescription date and categorising each patient at 12 months before the index date as: no COX2 inhibitors use, current COX2 inhibitors user, recent user (stopped the drugs at 13-24 months before the index date) and past user (stopped the drugs at 25 or more months before the index date).

\section{Statistical analysis}

We used conditional multivariate logistic regression to estimate odds ratios (ORs) with 95\% confidence intervals (CIs) associated with COX2 inhibitor use compared with non-use for cancers overall and each specific cancer. We calculated unadjusted ORs and adjusted for the potential confounding variables listed above, in which patients were classified as users of each medication if they had at least one prescription for NSAIDs or aspirin and at least two prescriptions for statins, hormone replacement therapy and oral contraceptives.

We carried out multiple imputation (Royston, 2005) with Stata ICE programs to replace missing values of BMI, smoking status and Townsend deprivation scores. We applied Rubin's rules to five imputed data sets to combine effect estimates for each cancer separately. We removed rheumatoid arthritis patients in an additional analysis to eliminate its potential effect on the risk of haematological malignancies Thomas et al, 2000).

We used all the available data on the QResearch database, hence, did not do a pre-study sample size calculation. We chose a $1 \%$ significance level to determine statistical significance to account for the multiple outcomes. Stata v10 (StataCorp LP, College Station, TX, USA) was used for all analyses.

\section{RESULTS}

There were 118780 patients with diagnoses of cancers in the study period matched with 588797 controls. Of the patients with cancer, 3810 with secondary cancers and 36 with inapplicable cancers (e.g., male/cervical cancer) were removed. For breast cancer, 1055 cases and 773 controls with a previous mastectomy or tamoxifen use were excluded. This left 113879 cases with a first diagnosis of cancer during the study period and 568958 matched controls. After removing 25754 cases and 206704 controls with $<6$ years of medical records or lacking a matched case or control, there were 88125 cases of primary cancer matched with 362254 controls, which were used in the analyses. The proportions of each cancer type in cases matched registration statistics in England for 2007 (Statistical Bulletin, 2010) for patients older than 30 years.

\section{Baseline characteristics}

Table 1 shows baseline characteristics for cases and controls. Fiftythree percent of cases were men; with a median age at diagnosis of 69 years (interquartile range: $60-77$ ). Overall, $76 \%$ of cases and $73 \%$ of controls had complete data for BMI, smoking status and Townsend deprivation score. Cases and controls had similar patterns of comorbidity. 
Table I Baseline characteristics for all cases with primary cancer and their matched controls with at least 6 years of medical records

\begin{tabular}{|c|c|c|}
\hline & $\begin{array}{c}\text { Cases } \\
(N=88 \text { I25) }\end{array}$ & $\begin{array}{c}\text { Controls } \\
(N=362254)\end{array}$ \\
\hline \multicolumn{3}{|l|}{ Sex } \\
\hline Female & 41749 (47.4) & $170173(47.0)$ \\
\hline Male & $46376(52.6)$ & $192081(53.0)$ \\
\hline \multicolumn{3}{|l|}{ Age band (years) } \\
\hline $30-54$ & $13|5|(\mid 4.9)$ & $49906($ ( 3.8$)$ \\
\hline $55-64$ & $19638(22.3)$ & $80107(22.1)$ \\
\hline $65-74$ & $26758(30.4)$ & | | $698(30.8)$ \\
\hline $75-84$ & $25013(28.4)$ & $106278(29.3)$ \\
\hline $85+$ & $3565(4.0)$ & $14265(3.9)$ \\
\hline \multicolumn{3}{|l|}{ Deprivation, Townsend quintile } \\
\hline 1, Most affluent & $22072(25.0)$ & $92287(25.5)$ \\
\hline 2 & $18998(21.6)$ & $79067(21.8)$ \\
\hline 3 & $17338(19.7)$ & $71358(19.7)$ \\
\hline 4 & $15325(17.4)$ & $61767(17.1)$ \\
\hline 5, Most deprived & 11896 (13.5) & 45971 ( 12.7$)$ \\
\hline Townsend missing & $2496(2.8)$ & $11804(3.3)$ \\
\hline \multicolumn{3}{|l|}{ Body mass index $\left(\mathrm{kg} \mathrm{m}^{-2}\right)$} \\
\hline $15-24$ & $26721(30.3)$ & $105883(29.2)$ \\
\hline $25-29$ & $27285(31.0)$ & $108803(30.0)$ \\
\hline $30-49$ & $12922(14.7)$ & $51413(14.2)$ \\
\hline Not recorded & $21197(24.1)$ & $96155(26.5)$ \\
\hline \multicolumn{3}{|l|}{ Smoking status } \\
\hline Non-smoker & $54307(61.6)$ & $233135(64.4)$ \\
\hline Ex-smoker & $7567(8.6)$ & $23842(6.6)$ \\
\hline Current smoker & $17275(19.6)$ & $54869(15.1)$ \\
\hline Not recorded & $8976(10.2)$ & $50408(13.9)$ \\
\hline \multicolumn{3}{|l|}{ Comorbidities } \\
\hline Cardiovascular disease & $14278(16.2)$ & $58123(16.0)$ \\
\hline Diabetes & $7 \mid 15(8.1)$ & $26802(7.4)$ \\
\hline Hypertension & $27104(30.8)$ & $109797(30.3)$ \\
\hline Osteoarthritis & $12807(14.5)$ & $52586(14.5)$ \\
\hline Rheumatoid arthritis & $1310(1.5)$ & $5132(1.4)$ \\
\hline Colitis $^{\mathrm{a}}$ & $124(1.1)$ & $293(0.6)$ \\
\hline Crohn's disease $^{\mathrm{a}}$ & $28(0.2)$ & $109(0.2)$ \\
\hline Benign breast disease $^{\mathrm{b}}$ & $1094(7.0)$ & $2937(4.7)$ \\
\hline Family history of breast cancer ${ }^{b}$ & $539(3.4)$ & $1249(2.0)$ \\
\hline \multicolumn{3}{|l|}{ Medications (in previous $13-72$ months) } \\
\hline Traditional NSAIDs & $35697(40.5)$ & | $40642(38.8)$ \\
\hline Aspirin & $19895(22.6)$ & $79067(21.8)$ \\
\hline Statins & $13621(15.5)$ & $54606(15.1)$ \\
\hline Hormone replacement therapy ${ }^{b}$ & $3289(21.0)$ & $10973(17.4)$ \\
\hline Oral contraceptive pill ${ }^{\mathrm{b}}$ & $523(3.3)$ & $1638(2.6)$ \\
\hline
\end{tabular}

Abbreviation: NSAID = non-steroidal anti-inflammatory drug. ${ }^{\mathrm{a}} \mathrm{O}$ the basis of cases with colorectal cancer and their controls only. ${ }^{b}$ On the basis of female cases with breast cancer and their controls only. Values are shown as numbers and \%.

\section{Exposure to COX2 inhibitors}

Overall 7.8\% (6901) of cases and 7.4\% (26974) of controls had at least one prescription for COX2 inhibitors. Most users (70\% cases, $70 \%$ controls) had no gap longer than 60 days between the first and last prescription, with $19 \%$ cases and $19 \%$ controls having only one gap longer than 60 days. Twenty-one percent of COX2 inhibitor users ( $21 \%$ cases, $21 \%$ controls) had prescriptions for more than 365 days (Figure 1) with median 20 prescriptions (interquartile range, 14-30 for cases, 14-31 for controls). Median duration of use for these long-term users was 25 months (interquartile range 17-37 for cases and 18-37 for controls) and median duration for short-term users was 2 months (interquartile range 1-4 for both cases and controls).
The most frequently prescribed COX2 inhibitors were rofecoxib (3.1\% cases, $3.0 \%$ controls), celecoxib ( $2.6 \%$ cases, $2.5 \%$ controls) and meloxicam (2.6\% cases, $2.4 \%$ controls). Other COX2 inhibitors were prescribed to $<1 \%$ cases and $1 \%$ controls. Most rofecoxib users were on low/medium dose ( $71 \%$ cases, $72 \%$ controls), most celecoxib users were on high dose ( $81 \%$ cases, $79 \%$ controls) and more than half of meloxicam users ( $65 \%$ cases, $65 \%$ controls) were on high dose.

A higher proportion of COX2 inhibitors users had hypertension, cardiovascular disease, diabetes, rheumatoid arthritis and osteoarthritis than non-users (Table 2).

Cancer of any site The analysis for cancer risk showed a significant association with any COX2 inhibitors use, although the OR (Table 3 ) was close to unity (OR 1.06, 95\% CI 1.03-1.09, $P<0.001$ ), and no association for long-term use (OR 1.02, 95\% CI $0.96-1.08, P=0.616)$. Analyses of trends for duration of use and dosage, as well as individual COX2 inhibitors use did not show significant associations with overall cancer risk (Table 4 and Supplementary information).

Colorectal cancer There was no association between any use of COX2 inhibitors and risk of colorectal cancer, but the association with long-term use was significant (OR 0.76, 95\% CI 0.63-0.92, $P=0.004)$. There was a significant trend for duration of use $\left(P_{\text {trend }}=0.004\right)$ with an OR of $0.66(95 \%$ CI $0.51-0.86, P=0.002)$ for more than 24 months of use. Risk of colorectal cancer stayed significantly decreased for long-term users who stopped COX2 inhibitors more than 2 years before the index date (OR 0.74, 95\% CI $0.60-0.92, P=0.007$ ).

Breast cancer Risk of breast cancer was not statistically significantly associated with overall COX2 inhibitor use, but there was a significant trend with duration of use $\left(P_{\text {trend }}=0.002\right)$ with an increased risk in long-term users (OR 1.24, 95\% CI 1.08-1.42, $P=0.003$ ), which stayed increased after stopping COX2 inhibitors more than 2 years before the index date (OR 1.23, 95\% CI $1.05-1.44, P=0.009$ ).

Haematological malignancies There was a significant association between risk of haematological malignancies and COX2 inhibitor use (OR 1.18, 95\% CI 1.07-1.31, $P=0.001$ ) with an even stronger association for long-term users (OR 1.38, 95\% CI 1.12-1.69, $P=0.002)$. There was a significant trend for duration of use $\left(P_{\text {trend }}<0.001\right)$ and an increased risk of $47 \%$ in users for more than 2 years $(P=0.008)$. Removing cases and controls with rheumatoid arthritis did not change the ORs. Meloxicam had the highest OR (OR 1.27, 95\% CI 1.08-1.50, $P=0.004$ ) for overall use, but others were not statistically significant. The risk in long-term users remained significantly increased after stopping COX2 inhibitors for more than 2 years before the index date (OR 1.40, 95\% CI 1.11-1.76, $P=0.005$ ).

The ORs for overall use in separate analyses for leukaemia, lymphoma and myeloma showed consistent increases, though only myeloma was significant (ORs $1.18,95 \%$ CI $1.02-1.36, P=0.030$; $1.21,95 \%$ CI $1.01-1.45, P=0.036$; and $1.43,95 \%$ CI $1.13-1.81$. $P=0.003$, respectively). Long-term use showed a stronger effect for lymphoma (ORs 1.20 , 95\% CI $0.88-1.64, P=0.246 ; 1.70,95 \% \mathrm{CI}$ $1.21-2.40, P=0.002$; and $1.38,95 \%$ CI $0.87-2.19, P=0.168$, for leukaemia, lymphoma and myeloma, respectively), with respective trends $\left(P_{\text {trend }}=0.071\right), \quad\left(P_{\text {trend }}=0.001\right)$ and $\left(P_{\text {trend }}=0.048\right)$ for actual months of use.

Lung cancer There were no significant associations for lung cancer. Long-term COX2 inhibitor users had a lower risk (OR 0.79, $95 \%$ CI $0.65-0.95, P=0.012$ ), but it was not statistically significant at the level of 0.01 . 
Risk of cancer in patients using COX2 inhibitors for more than 365 days in 13 to 72 months before the index date.

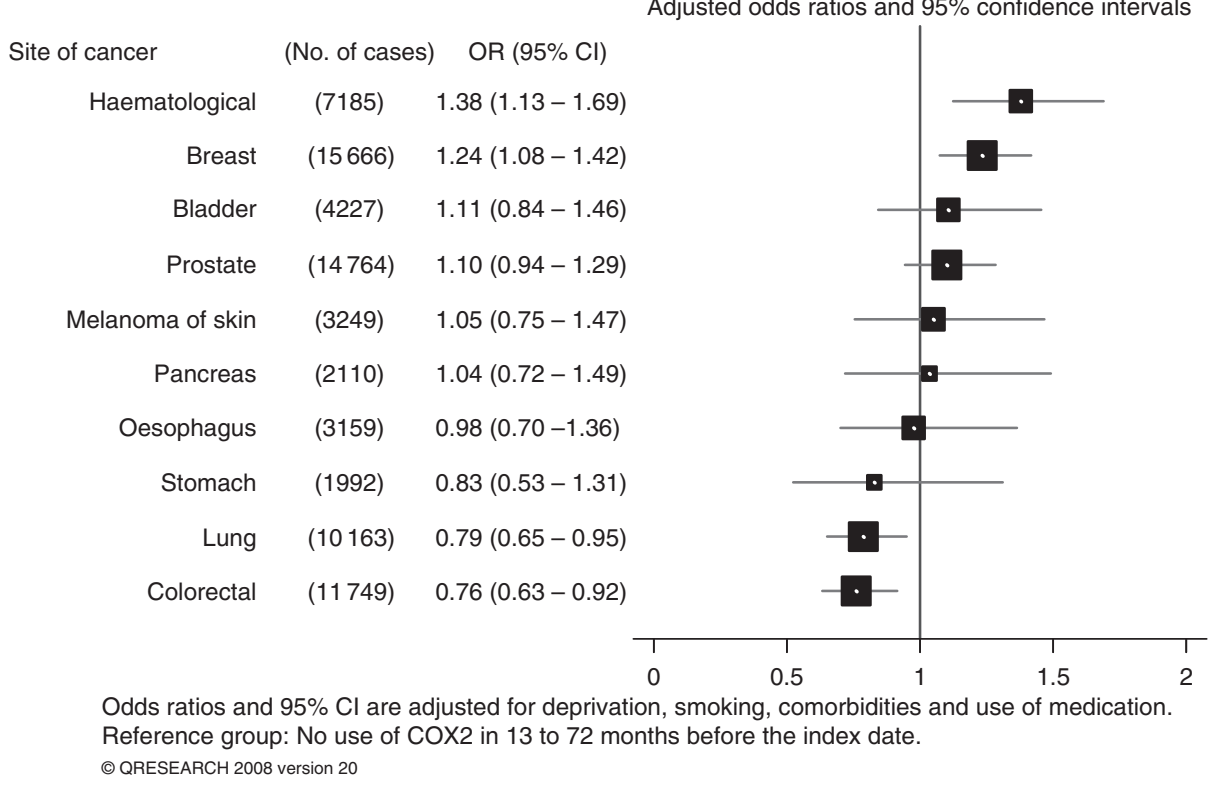

Figure I Risk of cancer in patients using COX2 inhibitors for more than 365 days in 13-72 months before the index date.

Other cancers There were no significant associations with COX2 inhibitor use for other cancers.

Other analyses No dose-response association with cancer was found for any site. No particular type of COX2 inhibitor overall use was associated with increased or decreased risk of cancer (except for blood cancer reported above).

\section{DISCUSSION}

The key findings from our study are that long-term use of selective COX2 inhibitors was associated with a $24 \%$ reduced risk of colorectal cancer, a $24 \%$ increased risk of breast cancer and a $38 \%$ increased risk of haematological cancer. No significant increases or decreases for other common cancers were found. Although the protective effect for colorectal cancer might have been hypothesised from theoretical and laboratory studies (Koki and Masferrer, 2002; Khan and Lee, 2009), we believe this is the first demonstration using general population clinical data.

\section{Comparison with other studies}

Many epidemiological studies have investigated the effects of nonspecified or combined (COX2 and traditional) NSAIDs on cancer risk (Garcia Rodriguez and Huerto-Alvarez, 2001; Sørensen et al, 2003; Jacobs et al, 2005; Hernández-Díaz and García Rodríguez, 2006; Bardia et al, 2007; Gallicchio et al, 2007). A number of them have suggested overall chemoprotective properties of NSAIDs for several cancers, in particular colorectal (Garcia Rodriguez and Huerto-Alvarez, 2001; Sørensen et al, 2003) and, for long-duration regular users, lung, prostate and breast cancer (Jacobs et al, 2005; Hernández-Díaz and García Rodríguez, 2006; Gallicchio et al, 2007).

There is less evidence for newer COX2 drugs, although laboratory and animal studies (Liu et al, 2004; Manish et al, 2005; Barnes et al, 2007; D'Arca et al, 2010) using COX2 inhibitors have shown possible decreases in cancer incidence. The reduced risk of colorectal cancer in our study was comparable with the $56 \%$ decreased risk of distal large bowel cancer in COX2 inhibitor users (Kim et al, 2008). COX2 inhibitor chemoprotective effects were also demonstrated in a randomised controlled trial for colorectal cancer prevention (Arber et al, 2006), although on patients with increased baseline risk because of previous history of adenomas. Although the trial was planned for 5 years of surveillance and treatment, it was stopped after 3.1 years because of adverse cardiovascular effects, but it still demonstrated a significant antitumour effect with risk reductions of $55-67 \%$ depending on celecoxib dose (Bertagnolli et al, 2006).

Our study's finding of an increased risk of breast cancer contrasts with findings from a hospital-based case-control study on selective COX-2 inhibitors (Harris et al, 2006), which demonstrated a significant risk reduction (OR $0.29,95 \%$ CI $0.14-0.59$ ) with daily use for at least 2 years. This study was very small (only 10 cases), and used questionnaire data and hence would have been subject to recall bias. Another study (Rahme et al, 2005) on menopausal women showed a reduction in breast cancer risk (OR 0.81, 95\% CI $0.68-0.97$ ) for COX2 inhibitor use of 90 days or longer, however, with shorter exposure (average of eight prescriptions). Although no other recent epidemiological study has looked at specific effects of COX-2 inhibitors, a number of studies have investigated effects of nonspecified or combined NSAID use on breast cancer (Gill et al, 2007; Kirsh et al, 2007; Ready et al, 2008), mostly finding no association. The mechanism of inhibiting of COX2 expression might differ for different types of traditional NSAIDs, and a cohort study (Marshall et al, 2005) demonstrated an increased risk in ibuprofen users but not in aspirin or other NSAIDs.

We showed increased risks for haematological malignancies, particularly lymphoma. Frequent traditional NSAID users with rheumatoid arthritis may have double the risk of having haematological cancers (Thomas et al, 2000), and one rheumatoid arthritis study showed an increased risk of lymphoma (Baecklund et al, 2006) from chronic inflammation. Removing rheumatoid arthritis patients, left our results unchanged, suggesting an effect from COX2 inhibitors rather than from the condition. Another meta-analysis demonstrated no association between NSAIDs and non-Hodgkin lymphoma (Bernatsky et al, 2007) risk, but the only study on COX2 inhibitors found a possible increased risk 
Table 2 Baseline characteristics in cases and controls COX2 users and non-users (at least one prescription in 13 to 72 months before index date)

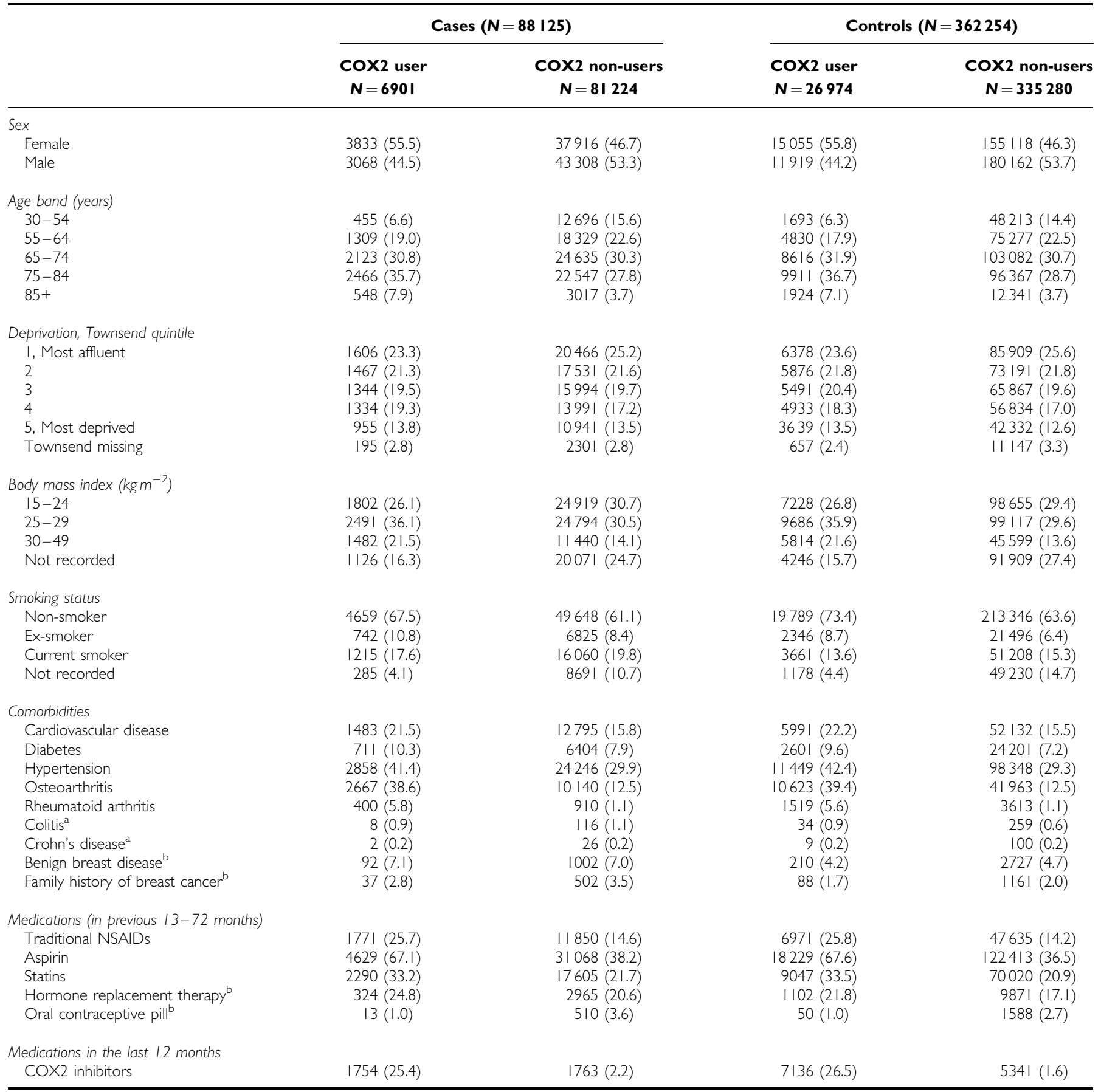

Abbreviations: $\mathrm{COX} 2$ = cyclooxygenase-2; NSAID = non-steroidal anti-inflammatory drug. ${ }^{\mathrm{a}}$ On the basis of cases with colorectal cancer and their controls, only. ${ }^{\mathrm{b}}$ On the basis of female cases with breast cancer and their controls, only. Values are shown as numbers and \%.

associated with regular use (Flick et al, 2006) (OR 1.58, 95\% CI $0.68-3.67$ ). A recent study (Chang et al, 2010) also demonstrated an increased risk of Hodgkin lymphoma, associated with COX2 inhibitors.

There is no established biological mechanism explaining the associations between COX2 inhibitors and risk of breast or blood cancers, and further exploration is needed.

We found no significant reduction of lung cancer risk in patients with over 1 year use of COX2 inhibitors, although there was some indication of a decreased risk (OR $0.79,95 \%$ CI $0.65-0.95$ ), in contrast to a very small study reporting a $60 \%$ reduction for COX2 inhibitor use of 2 years or more (Harris et al, 2007) (22 cases) with inevitable recall bias. A larger case-control study demonstrated a reduction of risk (Hernández-Díaz and García Rodríguez, 2006), based on all NSAIDS, but no significant association for COX2 inhibitors.

\section{Strengths and limitations}

The study was substantially larger than earlier studies, including information from all patients, including those with short survival. There is no recall bias, as details of prescriptions and confounding 
Table 3 Use of selective COX2 inhibitors (at least one prescription) in cases and in controls in 13 to 72 months before the index date by cancer site

\begin{tabular}{|c|c|c|c|c|c|c|c|}
\hline Cancer & $\begin{array}{c}\text { Total } \\
\text { number } \\
\text { of cases }\end{array}$ & $\begin{array}{l}\text { Total } \\
\text { number of } \\
\text { controls }\end{array}$ & $\begin{array}{l}\text { No. of COX2 } \\
\text { inhibitors users } \\
\text { in cases (\%) }\end{array}$ & $\begin{array}{c}\text { No. of COX2 } \\
\text { inhibitors users } \\
\text { in controls (\%) }\end{array}$ & $\begin{array}{l}\text { Unadjusted OR } \\
\qquad(95 \% \mathrm{Cl})^{\mathrm{a}}\end{array}$ & $\begin{array}{c}\text { Adjusted OR } \\
(95 \% \mathrm{Cl})^{a, b}\end{array}$ & $\begin{array}{c}\text { Adjusted } \\
\text { P-value }\end{array}$ \\
\hline Breast $^{c}$ & 15666 & 62938 & I304 (8.3) & $5046(8.0)$ & $1.09(1.02-1.17)$ & $1.07(1.00-1.15)$ & 0.047 \\
\hline Colorectal $^{d}$ & 11749 & 48624 & $866(7.4)$ & $3752(7.7)$ & $0.97(0.90-1.05)$ & $0.99(0.91-1.08)$ & 0.817 \\
\hline Lung & 10163 & 42415 & $845(8.3)$ & $3500(8.3)$ & $1.03(0.95-1.12)$ & $1.00(0.91-1.09)$ & 0.922 \\
\hline Haematological & 7185 & 29162 & $634(8.8)$ & $2104(7.2)$ & $1.30(1.18-1.44)$ & $1.18(1.07-1.31)$ & 0.001 \\
\hline Oesophagus & 3159 & $1304 \mid$ & $222(7.0)$ & 941 (7.2) & $0.99(0.85-1.16)$ & $1.03(0.88-1.21)$ & 0.710 \\
\hline Pancreas & 2110 & 8762 & $189(9.0)$ & $716(8.2)$ & $1.11(0.94-1.33)$ & $1.12(0.94-1.35)$ & 0.215 \\
\hline Stomach & 1992 & 8279 & $143(7.2)$ & $573(6.9)$ & $1.07(0.87-1.30)$ & $1.03(0.84-1.27)$ & 0.747 \\
\hline All cancers & 88125 & 362254 & $6901(7.8)$ & $26974(7.4)$ & $1.09(1.06-1.12)$ & $1.06(1.03-1.09)$ & $<0.001$ \\
\hline
\end{tabular}

Abbreviations: $\mathrm{Cl}=$ confidence interval; $\mathrm{COX} 2=$ cyclooxygenase-2; $\mathrm{OR}=$ odds ratio. ${ }^{\mathrm{a} C o m p a r e d}$ with no use. ${ }^{\mathrm{b}}$ Adjusted for Townsend quintile, body mass index, smoking status, myocardial infarction, coronary heart disease, diabetes, hypertension, stroke, rheumatoid arthritis, osteoarthritis, use of other lipid-lowering drugs, non-steroidal antiinflammatory drugs, COX2 inhibitors and aspirin. ${ }^{\mathrm{C} A l s o}$ adjusted for family history of breast cancer, use of oral contraceptives and hormone replacement therapy. ${ }^{\mathrm{d}}$ Also adjusted for colitis and Crohn's disease.

Table 4 Cumulative duration of COX2 inhibitors use in cases and controls in 13-72 months before the index date by cancer site

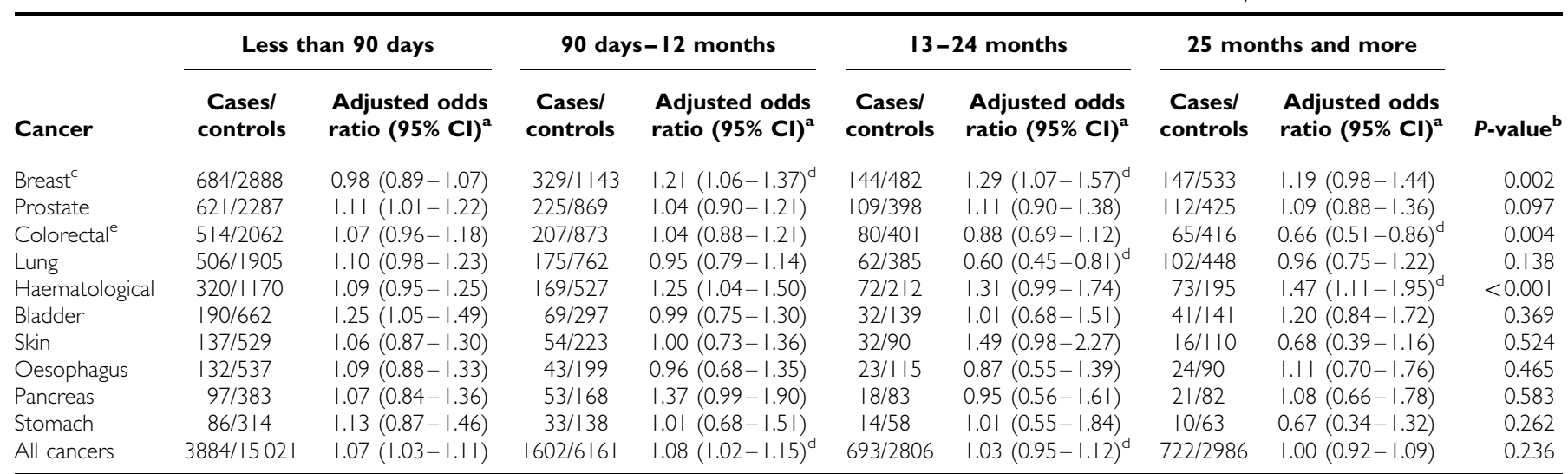

Abbreviations: $\mathrm{Cl}=$ confidence interval; $\mathrm{COX} 2=$ cyclooxygenase-2. adjusted for Townsend quintile, body mass index, smoking status, myocardial infarction, coronary heart disease, diabetes, hypertension, stroke, rheumatoid arthritis, osteoarthritis, use of other lipid-lowering drugs, non-steroidal anti-inflammatory drugs, COX2 inhibitors, aspirin and compared with no use. ${ }^{b}$ Trend test based on number of months prescribed. ${ }^{\mathrm{C}}$ Also adjusted for family history of breast cancer, use of oral contraceptives, hormone replacement therapy. ${ }^{d} P$-value $<0.01$. ' Also adjusted for colitis and Crohn's disease.

factors were recorded prospectively before the index date. Bias from misclassification of diagnoses was unlikely because accuracy and completeness of records in general practices is high (Hippisley-Cox et al, 2003; Herrett et al, 2010). Matching controls on sex, age, practice and calendar year removed effects from these confounding factors and we adjusted for a number of other confounding variables. Although we used a $1 \%$ level to define statistical significance level, some of our findings might still have arisen from multiple significance testing. Bias from misclassification of COX2 inhibitor use was unlikely as over $99 \%$ of all repeat prescriptions are computer recorded (Department of Health, 2007), and underestimation of use was unlikely as these drugs are prescription-only.

We did not adjust for certain cancer risk factors, such as physical activity, women's reproductive history, alcohol use and diet, because these are not consistently recorded. There may, therefore, be residual confounding if these factors are associated with COX2 inhibitor use. Body mass index, smoking status and deprivation had missing values in $22 \%$ of cases and in $25 \%$ of controls, and we used multiple imputation to replace these values. Although our data contain detailed information on drug prescriptions, this may not reflect the actual use. There is no reason to think that any non-adherence would systematically differ between cases and controls, however, such misclassification might have biased the ORs towards one making the associations weaker. There may be residual confounding because of over-the-counter use of NSAIDs and aspirin, which was not accounted for in the analyses. There was no information about cancer stage and it is unknown whether the symptoms before diagnosis led to COX2 inhibitor use. The possibility of this was minimised by ignoring prescriptions in the last year before the index date.

\section{Summary}

We have conducted a large population-based case-control study examining the association of selective COX-2 inhibitors with risk of common cancers in the general population and found a reduced risk of colorectal cancer, but increased risks of breast and haematological malignancies in long-term COX2 inhibitor users, which did not decrease after cessation. This was a very broad study covering a range of cancers, each of which, though related, are complex and exhibit significant variations in terms of disease mechanisms and progression, symptoms and treatments. The primary value of the study is, therefore, as a comprehensive overview, identifying the relative potential of different areas for further focused investigation. Although some significant findings are reported, further studies are suggested, in particular, in the areas of breast and blood cancers. 


\section{ACKNOWLEDGEMENTS}

We acknowledge the contribution of EMIS for expertise in creating and maintaining QResearch and to the EMIS practices, which contribute data, without whom this research would not be possible.

\section{Author contributions}

YV contributed to the study design, undertook the literature review and the primary analysis as well as the first interpretation and wrote the first draft of the paper. YV is the guarantor of the study. CC contributed to the development of the idea, design, analysis, interpretation and drafting of the paper. $\mathrm{JH}-\mathrm{C}$ had the original idea for this study, extracted the data, contributed to design, interpretation and commented on the draft of the paper.

\section{Conflict of interest}

$\mathrm{JH}-\mathrm{C}$ is co-director of QResearch (a not for profit organization, that is, a joint partnership between the University of Nottingham and EMIS, the leading commercial supplier of IT for $60 \%$ of general practices in the United Kingdom) and director of ClinRisk, which produces software to ensure the reliable and updatable implementation of clinical risk algorithms within clinical computer systems to improve patient care. This work and any views expressed within it are solely those of the authors and not of any affiliated bodies or organisations.

Supplementary Information accompanies the paper on British Journal of Cancer website (http://www.nature.com/bjc)

\section{REFERENCES}

Arber N, Eagle CJ, Spicak J, Rácz I, Dite P, Hajer J (2006) Celecoxib for the prevention of colorectal adenomatous polyps. $N$ Engl J Med 355: 885-895

Baecklund E, Iliadou A, Askling J, Ekbom A, Backlin C, Granath F, Catrina AI, Rosenquist R, Feltelius N, Sundström C, Klareskog L (2006) Association of chronic inflammation, not its treatment, with increased lymphoma risk in rheumatoid arthritis. Arthritis Rheum 54(3): $692-701$

Bardia A, Ebbert J, Vierkant R, Limburg P, Anderson K, Wang A, Olson J, Vachon C, Cerhan J (2007) Association of aspirin and nonaspirin nonsteroidal anti-inflammatory drugs with cancer incidence and mortality. J Natl Cancer Inst 99(11): 881-889

Barnes NLP, Warnberg F, Farnie G, White D, Jiang W, Anderson E, Bundred NJ (2007) Cyclooxygenase-2 inhibition: effects on tumour growth, cell cycling and lymphangiogenesis in a xenograft model of breast cancer. $\mathrm{Br} J$ Cancer 96(4): 575-582

Bernatsky S, Lee JL, Rahme E (2007) Non-Hodgkin's lymphoma-metaanalyses of the effects of corticosteroids and non-steroidal antiinflammatories. Rheumatology 46(4): 690-694

Bertagnolli MM, Eagle CJ, Zauber AG, Redston M, Solomon SD, Kim K, Tang J, Rosenstein RB, Wittes J, Corle D, Hess TM, Woloj GM, Boisserie F, Anderson WF, Viner JL, Bagheri D, Burn J, Chung DC, Dewar T, Foley TR, Hoffman N, Macrae F, Pruitt RE, Saltzman JR, Salzberg B, Sylwestrowicz T, Gordon GB, Hawk ET (2006) Celecoxib for the prevention of sporadic colorectal adenomas. $N$ Engl J Med 355(9): 873-884

British Medical Association, Royal Pharmaceutical Society (2010) British National Formulary, vol. 59. British Medical Journal Publishing Group and Pharmaceutical Press: London

Chan FKL, Lanas A, Scheiman J, Berger MF, Nguyen H, Goldstein JL (2010) Celecoxib versus omeprazole and diclofenac in patients with osteoarthritis and rheumatoid arthritis (CONDOR): a randomised trial. Lancet 376(9736): $173-179$

Chang E, Cronin-Fenton D, Friis S, Hjalgrim H, Sørensen H, Pedersen L (2010) Aspirin and other nonsteroidal anti-inflammatory drugs in relation to Hodgkin lymphoma risk in northern Denmark. Cancer Epidemiol Biomarkers Prev 19(1): 59-64

D'Arca D, LeNoir J, Wildemore B, Gottardo F, Bragantini E, Shupp-Byrne D, Zanesi N, Fassan M, Croce CM, Gomella LG, Baffa R (2010) Prevention of urinary bladder cancer in the FHIT knock-out mouse with Rofecoxib, a Cox-2 inhibitor. Urol Oncol 28(2): 189-194

Department of Health (2007) NHS Repeat Dispensing Schemes In England. Department of Health: London

Flick ED, Chan KA, Bracci PM, Holly EA (2006) Use of nonsteroidal antiinflammatory drugs and non-Hodgkin lymphoma: a populationbased case-control study. Am J Epidemiol 164(5): 497-504

Gallicchio L, Visvanathan K, Burke A, Hoffman SC, Helzlsouer KJ (2007) Nonsteroidal anti-inflammatory drugs and the risk of developing breast cancer in a population-based prospective cohort study in Washington County, MD. Int J Cancer 121: 211-215

Garcia Rodriguez LA, Huerto-Alvarez C (2001) Reduced risk of colorectal cancer among long-term users of asprin and nonaspirin nonsteroidal antiinflammatory drugs. Epidemiology 12(1): 88-93
Gill JK, Maskarinec G, Wilkens LR, Pike MC, Henderson BE, Kolonel LN (2007) Nonsteroidal antiinflammatory drugs and breast cancer risk: the multiethnic cohort. Am J Epidemiol 166(10): 1150-1158

Harris RE, Beebe-Donk J, Alshafie GA (2006) Reduction in the risk of human breast cancer by selective cyclooxygenase-2 (cox-2) inhibitors. BMC Cancer 6: 27

Harris RE, Beebe-Donk J, Alshafie GA (2007) Reduced risk of human lung cancer by selective cyclooxygenase 2 (cox-2) blockade: results of a case control study. Int J Biol Sci 3: 328-334

Hernández-Díaz S, García Rodríguez L (2006) Nonsteroidal anti-inflammatory drugs and risk of lung cancer. Int J Cancer 120: 1565-1572

Herrett E, Thomas SL, Schoonen WM, Smeeth L, Hall AJ (2010) Validation and validity of diagnoses in the general practice research database: a systematic review. Br J Clin Pharmacol 69(1): 4-14

Hippisley-Cox J, Pringle M, Cater R, Wynn A, Hammersley V, Coupland C, Hapgood R, Horsfield P, Teasdale S (2003) The electronic record in primary care - regression or progression? Cross-sectional survey. $B M$ J 326: $1439-1443$

Hippisley-Cox J, Vinogradova Y, Coupland C, Pringle M (2005) Comparison of key practice characteristics between general practices in England and Wales and general practices in the QResearch data. Report to the Health and Social Care Information Centre. University of Nottingham. Report no. R 21

Jacobs E, Rodriguez C, Mondul A, Connell C, Henley S, Calle E, Thun M (2005) A large cohort study of aspirin and other nonsteroidal antiinflammatory drugs and prostate cancer incidence. J Natl Cancer Inst 97: $975-980$

Khan MNA, Lee YS (2009) Cyclooxygenase inhibitors: scope of their use and development in cancer chemotherapy. Med Res Rev 31(2): $161-201$

Kim S, Martin C, Galanko J, Woosley JT, Schroeder JC, Keku TO, Satia JA, Halabi S, Sandler RS (2008) Use of nonsteroidal antiinflammatory drugs and distal large bowel cancer in whites and African Americans. $\mathrm{Am} \mathrm{J}$ Epidemiol 168(11): $1292-1300$

Kirsh VA, Kreiger N, Cotterchio M, Sloan M, Theis B (2007) Nonsteroidal antiinflammatory drug use and breast cancer risk: subgroup findings. Am J Epidemiol 166(6): 709-716

Koki A, Masferrer J (2002) Celecoxib: a specific COX-2 inhibitor with anticancer properties. Cancer Control 9(2 Suppl): $28-35$

Liu X, Yue P, Zhou Z, Khuri F, Sun S (2004) Death receptor regulation and celecoxib-induced apoptosis in human lung cancer cells. J Natl Cancer Inst 96(23): 1769-1780

Manish I, Patel MI, Subbaramaiah K, Du B, Chang M, Yang P, Newman RA, Cordon-Cardo C, Thaler HT, Dannenberg AJ (2005) Celecoxib inhibits prostate cancer growth: evidence of a cyclooxygenase-2-independent mechanism. Clin Cancer Res 11: 1999-2007

Marshall SF, Bernstein L, Anton-Culver H, Deapen D, Horn-Ross PL, Mohrenweiser H, Peel D, Pinder R, Purdie DM, Reynolds P, Stram D, West D, Wright WE, Ziogas A, Ross RK (2005) Nonsteroidal antiinflammatory drug use and breast cancer risk by stage and hormone receptor status. J Natl Cancer Inst 97(11): 805-812

MHRA (2005) Updated Advice On the Safety of Selective Cox-2 Inhibitors. Medicines and Healthcare products Regulatory Agency: London 
Nakamura S, Kobayashi M, Shibata K, Sahara N, Shigeno K, Shinjo K, Naito K, Hayashi H, Ohnishi K (2006) Etodolac induces apoptosis and inhibits cell adhesion to bone marrow stromal cells in human myeloma cells. Leuk Res 30(2): 123 - 135

Nakanishi Y, Kamijo R, Takizawa K, Hatori M, Nagumo M (2001) Inhibitors of cyclooxygenase-2 (COX-2) suppressed the proliferation and differentiation of human leukaemia cell lines. Eur J Cancer 37(12): $1570-1578$

National Statistics (2000) Key Health Statistics from General Practice 1998: Series MB6 (no 2). Office for National Statistics: London

Rahme E, Ghosn J, Dasgupta K, Rajan R, Hudson M (2005) Association between frequent use of nonsteroidal anti-inflammatory drugs and breast cancer. BMC Cancer 5(1): 159

Ready A, Velicer C, McTiernan A, White E (2008) NSAID use and breast cancer risk in the VITAL cohort. Breast Cancer Res Treat 109(3): $533-543$

Royston P (2005) Multiple imputation of missing values: update of ice. Stata J 5(4): $527-536$

Smith N, Wilson A, Weekes T (1995) Use of Read codes in development of a standard data set. BMJ 311: $313-315$
Solomon SD, McMurray JJV, Pfeffer MA, Wittes J, Fowler R, Finn P, Anderson WF, Zauber A, Hawk E, Bertagnolli M (2005) Cardiovascular risk associated with celecoxib in a clinical trial for colorectal adenoma prevention. $N$ Engl J Med 352(11): $1071-1080$

Sørensen HT, Friis S, Nørgård B, Mellemkjær L, Blot WJ, McLaughlin JK, Ekbom A, Baron JA (2003) Risk of cancer in a large cohort of nonaspirin NSAID users: a population-based study. Br J Cancer 88: 1687-1692

Statistical Bulletin (2010) Cancer Statistics Registration: Registrations of Cancer Diagnosed in 2007, England: Series MB1 (no 38). Office for National Statistics: London

The NHS Information Centre for health and social care (2008) Prescription Cost Analysis, England 200. Prescribing Support Unit: London

Thomas E, Brewster DH, Black RJ, Macfarlane GJ (2000) Risk of malignancy among patients with rheumatic conditions. Int J Cancer 88(3): 497-502

Tran-Thanh D, Buttars S, Wen Y, Wilson C, Done S (2010) Cyclooxygenase2 inhibition for the prophylaxis and treatment of preinvasive breast cancer in a her-2/neu mouse model. Cancer Prev Res 3(2): 202-211

Westlake S, Office for National Statistics (2008) Report: cancer incidence and mortality in the United Kingdom and constituent countries, 2003-2005. HSQ 40 